\title{
SPATIAL DEVELOPMENT OF SLOVENIAN TOWNS IN THE LAST DECADE
}

\author{
Vladimir Drozg \\ Department of Geography, Faculty of Education, University of Maribor, \\ Koroška cesta 160, 2000 Maribor, Slovenia \\ e-mail: vlado.drozg@uni-mb.si
}

\begin{abstract}
This contribution intends to show some characteristics of the special development of Slovenian towns in the last decade. Trends of spatial development are more or less similar in all towns, irrespective of their size, economic orientation of the town and development of the gravitational area. The main caracteristics is that the majority of Slovenian towns gradually moves from a high density compact town into a dispersed, regional town.
\end{abstract}

Key words: towns, spatial development, Slovenia

\section{INTRODUCTION}

The term spatial development describes the actual physical construction of a town. A synonym construction development can also be used.Spatial development can be performed in three ways:

- through construction or arrangement of building sites which have so far not had an urban function. This means that one changes the purpose of land plots from rural (agricultural or wooded) into urban, which usually happens in the town's surroundings or on the fringe of the town, lately also in the outskirts. This can also be done through erecting buildings on an empty plot of land within a built-up area.

- through restructuring the purpose of plots of land (construction of towns). This means that the purpose of land usage is changed or the usage as such is altered - i.e. the original/ primary urban activity is changed into a secondary one, or that the primary usage is intensified.

- through building or functional improvement of premises which can be limited to one premise or several premises.

The intention of this contribution is to show characteristics of spatial development of Slovenian towns. 
Some methodological explanations prior to main contribution:

- we have thoroughly analysed 5 towns (Maribor, Celje, Koper, Slovenj Gradec and Ptuj), we also considered individual cases from other Slovenian towns. An appropriate remark would be the question if we can generalise and project this situation on all Slovenian towns since we only analysed a few. As stated in the work of E. Lichtenberger, development factors within a set socio-economic system are very similar, the result of their effect is thus similar as well.

- data on construction intervention plays a crucial role. We have gathered this data by comparing cartographic material (air-shots from the years 1991 and 2000) and from urbanism documents as well as through findings from field work. We registered almost 1000 construction interventions in 5 towns. We believe that we included a majority of them, possibly excluding parts of individual construction and refurbished premises. The following data was collected for each intervention: when the intervention happened, location/area, surface, purpose of the land, type of premise, number of residential units and who is the investor.

- the basic method of work was to keep a record of areas that were built on between 1991 and 2002. The change in those areas or premises was understood as a conesquence of construction development.

- the main difficulty was limitation of towns, because we do not know for sure how far the suburban areas stretch. In case of smaller towns we only recorded the closest outskirts, in case of bigger towns those were recorded which had a demographic development index higher than 105 between the years 1991-2002.

- spatial development of towns can be documented in three ways: through the size of surface that was built on, location of this area and the number of individual construction interventions. Despite difficulties in obtaining this kind of information, the value of gathered facts is relatively small because we are talking of relative data. This data is only valid for the area and for buildings where the analysis was made.

\section{THE TOWN AND THE OUTSKIRTS - FROM SEPARATION TO UNIFICATION}

The analysis of spatial development of Slovenian towns in the 90's gives a fundamental recognition: the trend of spatial development is more or less the same in all Slovenian towns irrespective of size, economic direction of the town and development of gravitational area. The only thing that is different is the intensity of constructional development. Given that the social and economic processes as well as the legal frame for constructional intervention into that space are very similar, the results is a similar structure of towns. The most important processes that shape urban development in Slovenia include:

- growth of public welfare and consequently increase of social differentiation, different life-styles and the amount of social groups. All this is shown through different kinds of living arrangements and differentiation of space. 
- motorization and mobility of the population, life-style that is not tied to location

- dispersion of commercial activities and de-concentration of the population in the outskirts. Also increased is the difference of the town in demographic and physical sense.

Figure 1: Maribor - constructional development between 1992 - 2002

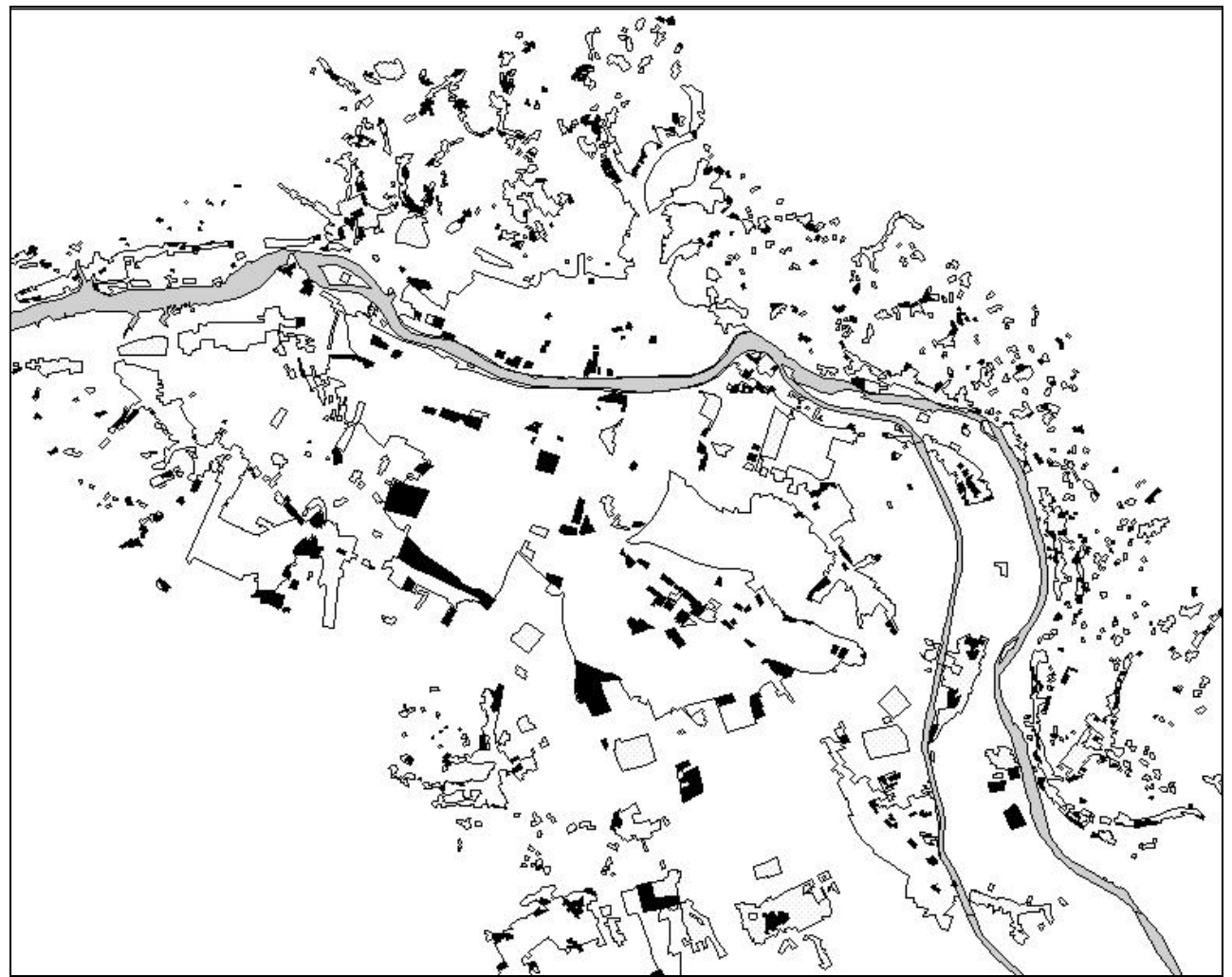

The consequence of these processes is a town that is composed of two parts: a compact, condensed part and a dispersed part which is composed of numerous suburbs and individual buildings. Both parts develop, but in a different way:

- the compact/condensed part shows predominance of new construction in built-in areas rather than extension of the outskirts. Compared to the outskirts, the latter hardly applies. If we divide the condensed part of town into the inner city, wider centre and the edge of town we see that the most intensive construction development happens in the wider centre and the edge of town, that means closer to the outskirts than the centre. The ratio of constructional interventions according to areas is $20: 30: 50$. Constructional activity moved from the city centre to the outskirts. The most intensive development can be found around access roads and by-passes as well as sub-centres (zones of central activity). This means mainly build-up empty plots of land, refurbishment of ex- 
Figure 2: Slovenj Gradec-purpose of usage of new areas between $1992-2002$

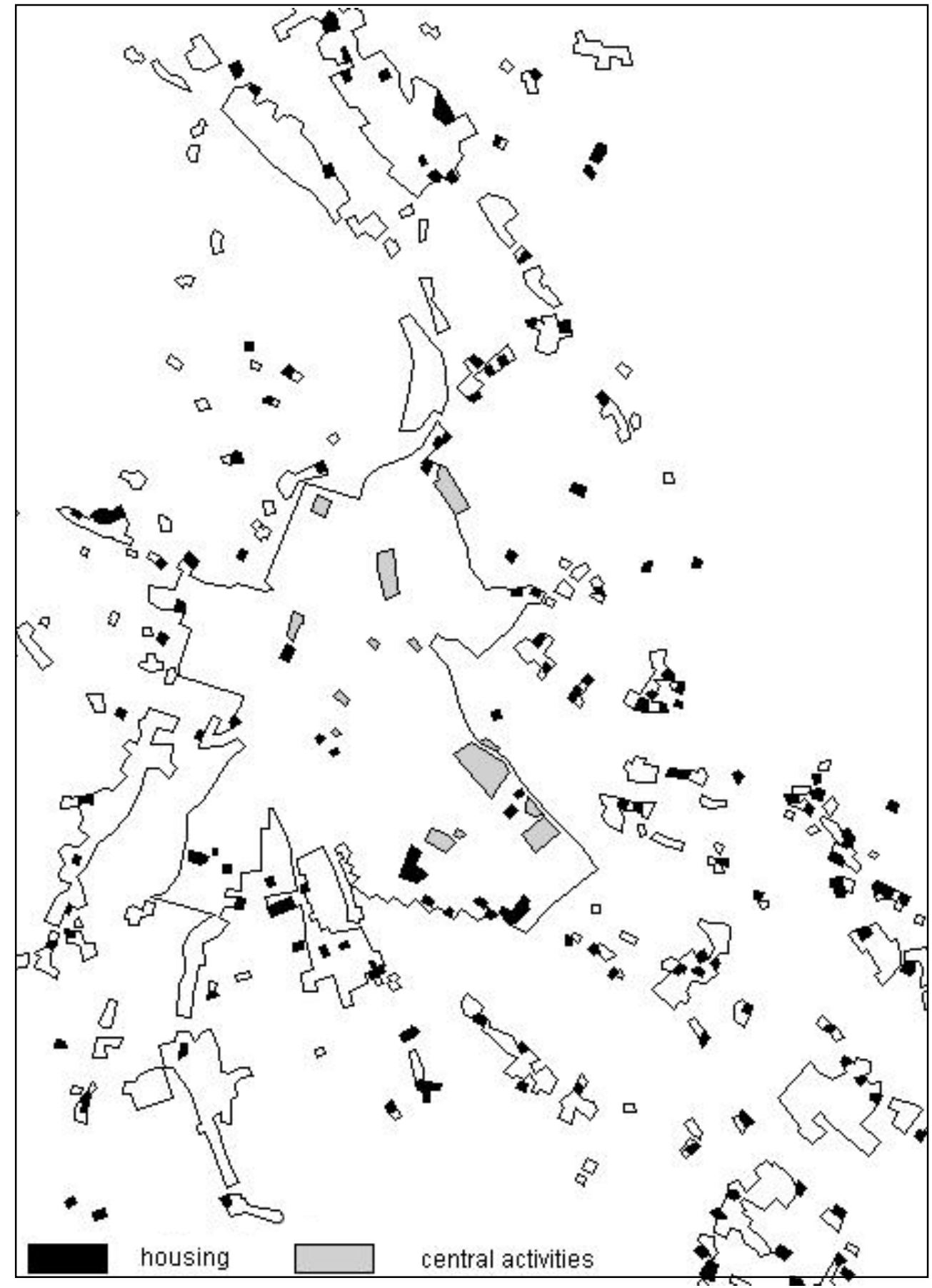


- isting premises and restructuring degraded areas. This is a consequence of past activities. E. Lichtenberger already pointed out the cyclical development of towns which shows that expansion is followed by construction, renovation, and restructuring. Constructional development of Slovenian towns between 1960-1980 shows expansion to new areas at the outskirts. Medieval town was surrounded by numerous blocks of flats which nevertheless included empty patches of land which are now attractive spots to build on. The other reason is that in the past, the majority of construction was meant for residential areas. After the introduction of market economy a higher activity is noted in the tertiary sector because it needs less space (only individual plots of land, possibly close to residential areas and with all communal facilities). Construction of compact towns and buildingup empty spaces can be found in bigger and smaller towns.

- outskirts show a trend of extension to new areas. Building-up empty spaces is rarely the case. Sub-urbanisation reached the Slovenian society at the end of the 1980s. The process was intensified even further in the 1990s. All towns had less inhabitants in 2002 than in 1991, some even less than in 1981. The sub-urbanisation process is limited especially to residential areas and not to movements of other urban activities to the outskirts. One more thing: in case of bigger towns the outskirts include several suburban settlements, in case of smaller towns only those who are in the proximity. The construction in the outskirts is very diffused and composed of individual residential premises and not blocks of flats or groups of houses. Bigger suburbs are only present in Ljubljana region and therefore an exception in other areas.

We can summarize that the majority of Slovenian towns gradually moves from a high density compact town into a dispersed, regional town. Ljubljana is therefore described as an urban agglomeration, similar statement can also be given about the urban area of coastal towns and partly Maribor region. A condensed town is being built-up and thus gains urban aspect. The outskirts are changed into a testing ground for urban activities, intertwining sleeping areas, shopping centres, prefabricated business quarters and warehouses. It is quite obvious that the construction of residential quarters moved from the town onto the outskirts. This created a amore obvious functional bipolarity - jobs on one hand and residences on the other. This trend raises the question of quality of residential areas in the outskirts, the question of taking care of public transportation and social segregation of town centres.

The size of individual construction areas is limited primarily to one or two premises, there are only a few bigger and more complex arrangements. Average size of constructional area was 1.1 ha.

\section{TERTIARISATION IS NOT ONLY AN ECONOMIC BUT ALSO A SPATIAL PROCESS}

If sub-urbanisation and construction are the most important processes that influence the physical structure of towns, tertiarisation is the most important process that sets their economic direction. The latter is also confirmed by the purpose of interventions into areas 
between 1991-2002. But it also proves that the purpose of plots of land in a densely constructed area differs from the outskirts.

Figure 3: Ptuj-disposition of tertiary activities in 1991 and 2002
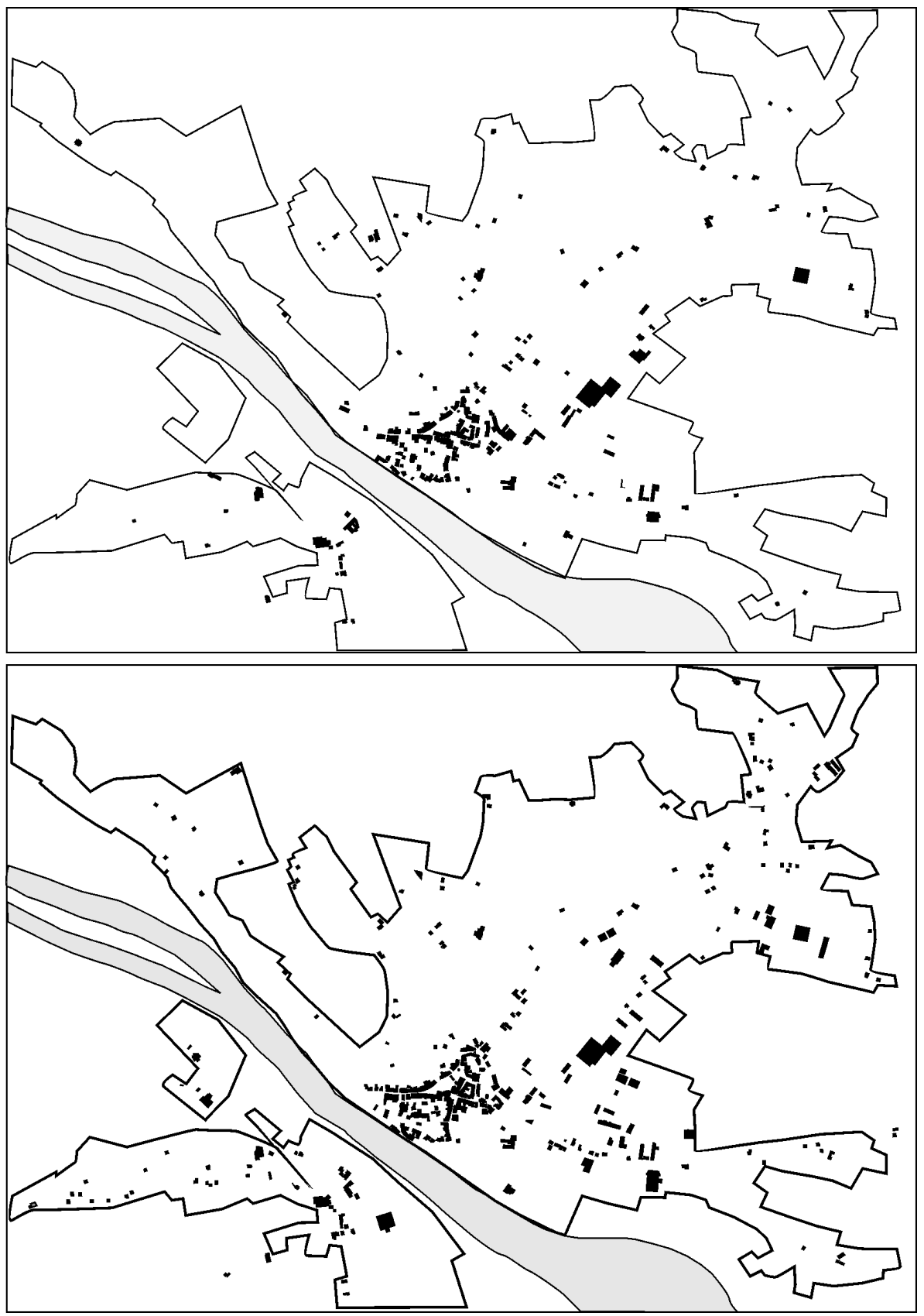
Majority of constructional intervention in a dense part of town was meant for business and commercial purposes first, followed by residential purposes and manufacture. The bigger the town, the more explicit the share of new areas, meant for central activities.

Location of constructional interventions with regards to activity shows a new economic structure of towns: business activities prevail in the city centre or close to it, commercial activities and services are located next to ring roads and major cross roads in the outskirts, residences are concentrated in the wider centre.

It is obvious that the historic centre which used to have the majority of commercial activities is changing. Shops replace apartments, catering industry, public offices and culture. New areas of central activities are now located on the outskirts, closer to the new demographic centre - tertiary activities are nowadays more dispersed around towns as they used to be.

Outskirts show predominance of residential areas and less of other urban activities. We find warehouses, manufactures, power supply, communal facilities - but only in bigger towns (most clearly in Ljubljana). Sub-urbanisation in Slovenia is currently limited to demographic relocation of the population and not to the functional transformation of the outskirts.

Commerce is among activities which have most radically changed the aspect of inner cities. Slovenia was caught by invasion of shopping centres after 1992. Almost each town received at least one until 2002. The quality of provision has grown considerably, compared to the situation prior to 1990 (which was rather poor). Commercial space/inhabitant increased from $0.5 \mathrm{~m}^{2}$ to $1.1 \mathrm{~m}^{2}$. However, this also means that the structure of towns has changed: majority of shopping centres can be found in the outskirts and not within the urban centre. An extreme case is Ljubljana where a "small town of big purchases" is being developed in the outskirts (as shown in the advertising slogan for the biggest shopping centre). The situation is no different in smaller towns: shopping centres are moving to the outskirts because the land is cheaper and because those are accessible by cars. The consequences are most obvious in the city centre of smaller towns which have hardly any commercial activity left.

\section{INDIVIDUAL RESIDENTIAL HOUSES AND BUSINESS PREMISES - A NEW IMAGE OF URBANISM?}

What kind of pattern arises in new parts of Slovenian towns? We have noticed two main trends after 1990s: one is construction of buildings which are, according to morphological characteristics, badly connected with the surroundings (that includes $2 / 3$ of all analysed cases); the other is opposed to that - new buildings are incorporated into the surroundings.

- compact areas show an increase of the so called business palaces, monument-like premises that are most often located next to the main access roads that lead into towns, close to open public areas, around major crossroads and in the outskirts. This concerns mostly business premises. 
- the second type of construction that is most often found in the wider centre of towns are buildings in street blocks which have taken on characteristics of multi-storey bourgeois houses and classicist ground plan. These are mainly residential houses, parts of which are devoted to business purposes.

- the number of refurbished and renovated premises has increased (especially those that are under preservation protection)

- residential areas are mainly organised according to the suburb concept. However, these are smaller and socially more differentiated an better equipped. Average density of population in residential areas with blocks of flats has decreased from 150 to 111 inhabitants/ha.

- types of construction in the outskirts differ according to the size of the town. We can say that individual houses prevail almost everywhere. However, in the outskirts of bigger towns (especially Ljubljana) those houses are more modern and more densely built. Outskirts of smaller towns keep the slightly less qualitative construction and form from the 70's or build-in formerly empty rural areas with houses. Settlements on the outskirts are to the major extent rural settlements changed into sleeping areas.

Morphometric characteristics of new residential areas show a changed approach regarding the usage of space. New construction is more rational than the one from the 1980s. It is obvious that one tries to decrease the size of ground plan and the methods of construction which enables higher density. Average density in these new residential areas is approximately 50 inhabitants/ha, which is, compared to 30 inhabitants/ha a huge difference. This kind of development is currently limited to big towns only, but we can expect similar changes in other towns as well. Higher density of construction brings a new image of urbanisation to Slovenian towns.

\section{CONSTRUCTIONAL DEVELOPMET MOVES FROM THE STATE INTO THE HANDS OF PRIVATE COMPANIES}

Who builds towns in Slovenia? Generally speaking, the bigger the town the smaller the share of individual investors and the bigger the share of investors - legal persons. Smaller companies, sort of consortiums, composed of several private companies are those who most often undertake construction activities. They finance the construction of residential suburbs or bigger residential buildings for the market. An important share in residential building construction falls onto private investors (mainly in construction of individual houses), mostly in the outskirts.

Frequent investors are companies who extend their manufacture and warehouse capacities and business premises (the most obvious is the share of commercial companies in the construction of shopping centres). The state finances construction of premises, meant for public and technical infrastructure. 
We can summarize that the share of the state in construction of towns is getting smaller (at least in comparison to the situation in the socialist period). This means that the role of private investors and their interests in town planning is increasing.

\section{References}

Drozg V., 1999: Nekatere morfološke značilnosti slovenskih mest. V: Dela 14, Ljubljana Kivell P., 1993: Land and the Citiy. London

Lichtenberger E., 1990: Stadtferfall und Stadterneuerung. Wien

Predikaka Boštjan, 2004: Terciarizacija Ptuja. Diplomsko delo. Pedagoška fakulteta, Maribor 